\title{
Being out of Work and Health among Younger Japanese Men: A Panel Data Analysis
}

\author{
Mari KAN ${ }^{1}$ \\ ${ }^{1}$ School of Economics, University of Hyogo, Japan \\ Received February 24, 2013 and accepted August 5, 2013 \\ Published online in J-STAGE August 13, 2013
}

\begin{abstract}
This paper examines the effect of being out of work, which is in a broader category of unemployment, on the physical and mental health of younger Japanese men using panel data. A fixed effects model, widely used to control for unobserved individual heterogeneity in panel data analysis, was used for this analysis. Using the first through the fifth waves of the Japanese Life Course Panel Survey, the first wave of which was conducted with people aged 20-40 yrs in 2007, it is found that being out of work has no observable effect on self-assessed physical health. However, being out of work has a negative effect on mental health as measured by the five-item version of the Mental Health Inventory. It is difficult to clearly distinguish the direction of causality even after controlling for individual heterogeneity that is constant over time. An analysis was done with a sub-sample to mitigate a possible reverse causality. The results consistently show that being out of work has a negative effect on mental health.
\end{abstract}

Key words: Unemployment, Being out of work, Self-assessed health, Mental health, Panel data, Fixed effects model

\section{Introduction}

In Japan, the issue of unemployment has not drawn much public attention until recently, because the unemployment rate in Japan has not been as high as in the other OECD countries. However, it rose gradually during the depression that lasted for about ten years starting in the early 1990 s, reaching $5 \%$ for the first time in 2001 . It rose to $5.5 \%$ in 2002 and 2003. Although the unemployment rate showed some improvement, decreasing to $3.9 \%$ in 2007, it rose again to $5.4 \%$ in 2010 after the economic slowdown, triggered by the Lehman Shock in the autumn of 2008 . Looking at the unemployment rate in 2010 by age group, we can see that it reaches about $4.0 \%$ in $40-54$ yr-old and rises to $10.3 \%$ in $20-24$ yr-old. Unemployment seems to

E-mail: mkan@econ.u-hyogo.ac.jp

(C)2013 National Institute of Occupational Safety and Health be becoming a serious problem among the youth in Japan even if the rate is still lower than that in some European countries $^{1)}$. Further, one of the most prominent features of unemployment in Japan is the high frequency of long-term unemployment (lasting for 12 months or more) ${ }^{2}$, often because the Japanese employment system has historically lacked flexibility.

The process by which drastic changes in the labor market affect the health of the working population, especially those who have lost their jobs, has not yet been examined in detail. Does losing one's job drastically reduce one's physical or mental health, and if so, to what extent? In Japan, a long-time social norm has dictated that people obtain a job immediately following graduation from school, a job they often must commit themselves to for their entire lives ${ }^{3)}$. In such a society, the effect of being unemployed on health could be much larger than in countries where the labor market is more flexible.

Since high unemployment has long been one of the 
most serious social problems among European countries, there is a considerable body of research examining the relationship between unemployment and health. While the negative correlation between unemployment and health is well known ${ }^{4-6)}$, it is also true that those who suffer from ill health are more likely to be unemployed. This is known as a self-selection bias. In order to cope with this bias, analyses using panel data are useful because they extract the individual effects that are constant across time. Using the European Community Household Panel for Finland for the period between 1996 and 2001, Böckerman and Ilmakunnas $^{7)}$ examined the relationship between unemployment and self-assessed health. Although cross-sectional analyses show that unemployment is strongly correlated with poor self-assessed health, panel analyses show that being unemployed has no effect on self-assessed health. This could mean that persons with poor health tend to be more likely among the unemployed.

However, even if the panel data analyses remove the effects that are constant over time, there are still time variant factors that simultaneously affect both employment status and health. Recently, several studies have utilized exogenous entries into unemployment - that is, unemployment caused by plant closures or business closings ${ }^{8)}$. Below are some recent findings in economics that utilize plant closure as an instrument for illustrating the causal effect of unemployment on health.

Browning and his colleagues ${ }^{9)}$ investigated whether job loss as a result of displacement can increase the likelihood of hospitalization due to stress-related diseases, using a random $10 \%$ sample of the male population of Denmark from 1981 to 1999 . They found that job loss was not related to increased hospitalization due to stress-related diseases. Regarding the effect of unemployment among the near-elderly population, an analysis using the Health and Retirement Study in the US found no causal effect of job loss on various measures of physical and mental health after controlling for possible reverse causality ${ }^{10)}$. From a labor economist perspective, Cai ${ }^{11)}$ used a simultaneous equation model to estimate the effect of employment status on health and the effect of health on employment status. He found that being in the labor force negatively affected health in men, but health affected labor force participation for both men and women.

As far as mental health is concerned, there is substantial literature on psychology. Goldman-Mellor and colleagues ${ }^{12)}$ conducted an extensive literature review on the relationship between individual job loss and mental health, as well as that between macroeconomic conditions and population level indicators of mental health. In the field of economics, Schmitz ${ }^{13)}$ used the German Socio-Economic Panel and found that unemployment caused by plant closure did not have a statistically significant influence on mental health. Using the Household, Income and Labour Dynamics in Australia (HILDA), Green ${ }^{14)}$ concluded that unemployment in general has a negative impact on mental health and subjective life satisfaction. It was also found that an individual's employability moderates that impact.

This study examines the effect of "being out of work," which is in a broader category of unemployment, on health by using Japanese micro-data. In particular, it focuses on the effects on the physical and mental health of younger male workers (20-40 yr old, as of 2007) and copes with individual heterogeneity by using a fixed effects model analysis. The author also conducts analyses using a sub-sample in order to mitigate the problem of reverse causality (i.e., that health determines employment status or motivation for a job search). Because women's labor force participation in Japan is strongly related to their marital status, the spousal tax deduction they receive from their husbands' income ${ }^{15)}$, whether they have children ${ }^{16)}$, and whether they are co-residing with their parents after marriage ${ }^{17)}$, it is more difficult to distinguish the effects specifically related to employment status in women. Therefore, this study focuses on the effect of being out of work on men.

\section{Subjects and Methods}

\section{Data}

The Japanese Life Course Panel Surveys (JLPS) carried out by the University of Tokyo Institute of Social Science was used for the analysis. The first wave of JLPS was conducted from January to April 2007. It consists of two panels, one with young adults (20-34 yr old) and the other with middle-aged adults (35-40 yr old). In conducting the JLPS 2007, a stratified random sampling method was adopted using the electoral and resident registries. The population was first stratified by age group and sex in order for the sample to equally represent each age group by sex. The questionnaire was distributed by mail. For the youth survey, 3,367 responses were obtained (response rate: $34.5 \%$ ), and for the middle-aged survey, 1,433 responses (response rate: $40.4 \%$ ). Follow-up surveys were conducted each subsequent year. So far, six waves of the survey have been completed.

The survey is designed to investigate how lifestyles and ways of thinking among the Japanese working population 
are changing according to the ever evolving labor market structure and the rapidly aging society. It consists of a wide range of questions regarding respondents' work, life, attitudes, and socioeconomic status. In addition, the JLPS asks respondents to report their self-assessed health, psychological condition, and employment status each year. Consequently, the author employed five waves (20072011) of the JLPS for the present study. The youth survey and the middle-aged survey were utilized altogether, but students were excluded from the sample.

\section{Outcome measures}

Self-assessed health

Self-assessed health and diagnosis or hospitalizations for stress-related diseases are major outcome measures in the literature that has examined the effect of unemployment. The JLPS asks respondents about their health condition in every wave, using the following question: "How would you rate your current health condition?" The possible answers are 1 ("very good"), 2 ("good), 3 ("general), 4 ("not very good"), and 5 ("bad"). Although the original answers were coded such that lower scores indicated better health, they were recoded so that higher scores indicated better health. Consequently, the scores range from one to five, with five indicating very good health.

\section{Psychological distress}

The index for mental health used in this paper is the total score from the five-item version of the Mental Health Inventory (MHI-5). The MHI-5 was proposed as a measure of mental health among the general population by Veit and Ware ${ }^{18)}$. This scale is thought to be useful for detecting the symptoms of depression, anxiety, and other emotional disorders. In addition, research has shown that the MHI-5 is a useful measure for depression screening compared with other measures ${ }^{19)}$. The validity of the Japanese version of the MHI- 5 was demonstrated by Yamazaki and colleagues ${ }^{20)}$. The actual items asked in the JLPS are as follows:

How often did you feel the following in the past month?

Quite nervous

Deeply depressed

Feeling calm and quiet

Feeling melancholic

Feeling pleasant

Answers range from one to five. Each answer was coded such that higher scores indicate better mental condition. The raw scores for each person could range from 5 to 25 . Each raw score was transformed to a 0 to 100 scale using the following formula.

Transformed Scale

$=\left[\frac{(\text { Actual raw score }- \text { lowest possible raw score })}{\text { Possible raw score range }}\right] \times 100$

Scores between 0 to 100 represent the percentage of the total possible score achieved ${ }^{21)}$. The internal consistency index was calculated. It is 0.776 and, therefore, plausible to use. Ware et $_{\text {al. }}{ }^{21)}$ recommends that if respondents leave one or more items in a multi-items scale blank, it should be estimated. In the JLPS, every item is filled out in a scale. Therefore, there was no such issue in this study.

\section{Explanatory variables}

The key explanatory variable in this study is "being out of work," which indicates that the respondent is in a state of not working, regardless of whether they are searching for a job. Recent research on the effect of unemployment utilizes exogenous job loss to identify the causal effect of unemployment. In labor economics, people who do not work but are searching for a job are defined as "unemployed." Thus, when we examine the causal effect of unemployment, the key explanatory variable should be strictly defined as "unemployed." However, in the present study, the author examines the effect of being out of work for two reasons.

The first reason pertains to the age of the respondents. Among men aged 20 to 40 , it is not common for them to be out of the labor force due to retirement. If those who have given up their job search because of long-term unemployment are excluded, the effect of unemployment could be underestimated. However, the reverse causality, which is that people are out of the labor force because of health problems, could be serious. The strategy to deal with this problem is presented in a later section. The second and minor reason for the use of "being out of work" is related to the sample size. The percentage of non-working people in the sample was very small. If only those who are "unemployed" were of concern in an estimation procedure, then variation within the group should be small for sound analyses. Therefore, those who are not searching for a job are included in the targeted group.

Other explanatory variables included in the models are age, age squared, education, marital status, and four year dummy variables. The variable age squared is included because the author assumes the effect of age is not merely linear. The models are estimated with and without household income per capita. Model 1, which included household income per capita as an explanatory variable, 
estimates the effect of being out of work on health after controlling for income loss. The main reason for using household income per capita instead of using the equivalent disposable income is that disposable income is not available in the data set. The reason why the author uses the actual number of household members as a denominator is because it reflects changes in household income more directly than the equivalent household members. Model 2, which does not include household income per capita, estimates the effect of being out of work on health after incorporating the effect of income loss.

\section{Statistical methods}

First, a pooled ordinary least square (OLS) analysis is used to examine the relationship between employment status and health. Since self-assessed health is not a continuous variable, using a non-linear functional form such as the ordered logit model might be ideal. However, the main focus of this research is using a panel method, and it is important to compare the results between a pooled analysis and a panel analysis. Since the algorithm estimating a fixed effect ordered logit model is beyond the scope of this journal, the author used a linear specification.

As stated before, individuals who suffer from ill health might tend to be unemployed, while it might also be true that losing their job affects their health. That is, the results from the pooled OLS analysis suffer from a self-selection bias. In order to address this bias, we used panel data, since they can be used to extract the individual-specific effects that are constant over time.

Panel data analysis

The foremost benefit of using panel data is that it allows one to control for individual heterogeneity ${ }^{22-24)}$. Panel data suggest that individuals are heterogeneous. Therefore, a cross-sectional study that does not control for this heterogeneity runs the risk of obtaining biased results. When health is modeled as a function of age, income, and employment status, it becomes susceptible to the influence of other variables that are difficult to measure or obtain. The omission of these variables could lead to bias in the resulting estimates. Panel data are able to control for these time-invariant variables, whereas a cross-sectional study cannot ${ }^{24)}$. Another benefit of using panel data is that they are better able to measure the response dynamics to a certain shock. They are also better able to identify and measure effects that are simply not detectable in pure cross-sectional data ${ }^{24)}$. Thus, in examining the effects of employment status, a panel analysis is superior overall to a cross-sectional analysis.

Fixed effects versus random effects models

Within the framework of panel data analysis, there is still a debate over fixed effects versus random effects models. The random effects model assumes exogeneity of all regressors with random individual effects. In contrast, the fixed effects model allows for endogeneity of all regressors with fixed individual effects ${ }^{25}$. In other words, the fixed effects model assumes that an unobserved individual effect correlates with every explanatory variable. In a case where the outcome variable is health, it is reasonable to think that the explanatory variables are correlated with several of unobserved individual effects. Therefore, a fixed effect model is assumed; however, another statistical test could have been more reliable. Thus, the author conducts the Houseman ${ }^{26)}$ test to decide which model is more appropriate $^{27)}$. StataSE 12 is used for the estimation. Within regression estimator and GLS estimator are employed in the fixed effect model and the random effect model, respectively.

Two other tests are conducted to determine which model is most appropriate. To examine whether a pooled model is more suitable than a random effects model, the author performs the Breusch and Pagan tests. Finally, an F-test is used to examine whether the pooled model is more suitable than the fixed effects model.

\section{Analysis with a sub-sample}

When we consider the effect of unemployment on health, reverse causality is a concern. Therefore, recent research conducted in Europe and the US used plant or business closures as a more ecologically valid experiment to distinguish the causal effects of unemployment on health. However, the individual level panel data in Japan do not include information on employers. Therefore, the present research conducted an analysis using a sub-sample, which excludes individuals who had always or often been restricted from housework or their job due to health problems. By doing so, the samples that would show strong reverse causality are excluded (i.e., that their health affects their work).

\section{Results}

The descriptive statistics of the sample are provided in Table 1. It is found that $4.7 \%$ of the sample is out of work. About $47 \%$ of respondents are college educated. These figures are compared with the statistical summary of the 
Table 1. Summary statistics of samples

\begin{tabular}{|c|c|c|c|c|c|c|}
\hline \multirow{2}{*}{ Variable } & \multicolumn{2}{|c|}{ All } & \multicolumn{2}{|c|}{ Employed } & \multicolumn{2}{|c|}{ Out of work } \\
\hline & Mean & Std. Dev. & Mean & Std. Dev. & Mean & Std. Dev. \\
\hline Self-rated health (1-5) & 3.374 & 0.913 & 3.402 & 0.896 & 2.805 & 1.052 \\
\hline MHI-5 score $(0-100)$ & 62.357 & 17.918 & 62.926 & 17.584 & 50.843 & 20.586 \\
\hline Being out of work & 0.047 & 0.212 & & & & \\
\hline Age & 33.124 & 5.548 & 33.147 & 5.549 & 32.663 & 5.526 \\
\hline Age squared & $1,127.996$ & 362.025 & $1,129.511$ & 362.161 & $1,097.302$ & 358.394 \\
\hline Education: High school or less & 0.322 & 0.467 & 0.318 & 0.466 & 0.398 & 0.490 \\
\hline Education: Junior high school & 0.211 & 0.408 & 0.208 & 0.406 & 0.276 & 0.448 \\
\hline Education: College or more & 0.467 & 0.499 & 0.474 & 0.499 & 0.326 & 0.469 \\
\hline Married & 0.445 & 0.497 & 0.438 & 0.496 & 0.599 & 0.491 \\
\hline Household income per person (yen) & $3,775,767$ & $2,258,387$ & $3,828,303$ & $2,247,007$ & $2,243,839$ & $2,047,145$ \\
\hline Number of observations & 7315 & & 6,971 & & 344 & \\
\hline $\begin{array}{l}\text { Number of observations (with information } \\
\text { about household income) }\end{array}$ & 5489 & & 5,307 & & 182 & \\
\hline
\end{tabular}

Table 2. Being out of work and self-assessed health

\begin{tabular}{|c|c|c|c|c|c|c|c|c|c|c|c|c|}
\hline & \multicolumn{6}{|c|}{ Model 1} & \multicolumn{6}{|c|}{ Model 2} \\
\hline & \multicolumn{2}{|c|}{ Pooled OLS } & \multicolumn{2}{|c|}{ Random effects model } & \multicolumn{2}{|c|}{ Fixed effects model } & \multicolumn{2}{|c|}{ Pooled OLS } & \multicolumn{2}{|c|}{ Random effects model } & \multicolumn{2}{|c|}{ Fixed effects model } \\
\hline & Coef. & Std. Err. & Coef. & Std. Err. & Coef. & Std. Err. & Coef. & Std. Err. & Coef. & Std. Err. & Coef. & Std. Err. \\
\hline Being out of work & $-0.524 * * *$ & 0.068 & $-0.307 * * *$ & 0.066 & -0.093 & 0.085 & $-0.565^{* * *}$ & 0.050 & $-0.292 * * *$ & 0.050 & $-0.110^{*}$ & 0.060 \\
\hline Age & -0.036 & 0.025 & -0.032 & 0.029 & & & -0.021 & 0.021 & -0.013 & 0.025 & & \\
\hline Age squared & 0.000 & 0.000 & 0.000 & 0.000 & 0.000 & 0.001 & 0.000 & 0.000 & 0.000 & 0.000 & 0.000 & 0.001 \\
\hline Junior high school & 0.031 & 0.034 & 0.040 & 0.049 & & & $0.053^{*}$ & 0.029 & 0.063 & 0.045 & & \\
\hline College or more & $0.164 * * *$ & 0.029 & $0.172 * * *$ & 0.041 & & & $0.205^{* * *}$ & 0.024 & $0.223 * * *$ & 0.037 & & \\
\hline Married & $-0.075^{* * *}$ & 0.026 & $-0.037^{*}$ & 0.022 & -0.023 & 0.025 & $-0.062 * * *$ & 0.022 & -0.025 & 0.018 & -0.010 & 0.020 \\
\hline Year 2008 & -0.037 & 0.036 & -0.038 & 0.028 & -0.063 & 0.053 & -0.002 & 0.031 & 0.002 & 0.022 & -0.014 & 0.043 \\
\hline Year 2009 & $-0.196^{* * *}$ & 0.037 & $-0.187^{* * *}$ & 0.029 & $-0.229 * *$ & 0.096 & $-0.163^{* * *}$ & 0.032 & $-0.157^{* * *}$ & 0.024 & $-0.184 * *$ & 0.078 \\
\hline Year 2010 & $-0.064 *$ & 0.039 & $-0.094 * * *$ & 0.031 & -0.174 & 0.143 & $-0.064 *$ & 0.034 & $-0.091^{* * *}$ & 0.026 & -0.146 & 0.115 \\
\hline Year 2011 & $-0.139 * * *$ & 0.038 & $-0.159 * * *$ & 0.031 & -0.256 & 0.191 & $-0.139 * * *$ & 0.033 & $-0.162 * * *$ & 0.027 & -0.234 & 0.153 \\
\hline Household income/Person & $0.000^{* * *}$ & 0.000 & $0.000^{* * *}$ & 0.000 & $0.000^{* * *}$ & 0.000 & & & & & & \\
\hline Constant & $4.130^{* * *}$ & 0.404 & $4.037 * * *$ & 0.462 & $3.299^{* * *}$ & 0.719 & $3.926 * * *$ & 0.341 & $3.723 * * *$ & 0.398 & $3.380^{* * *}$ & 0.571 \\
\hline sigma_u & & & 0.625 & & 0.782 & & & & 0.630 & & 0.766 & \\
\hline sigma_e & & & 0.628 & & 0.628 & & & & 0.629 & & 0.629 & \\
\hline rho & & & 0.498 & & 0.608 & & & & 0.501 & & 0.598 & \\
\hline Prob $>\chi^{2}$ & & & 0.000 & & & & & & 0.0000 & & & \\
\hline Prob $>\mathrm{F}$ & 0.0000 & & & & 0.0000 & & & & & & 0.0000 & \\
\hline R-squared & 0.044 & & 0.0437 & & 0.0135 & & 0.041 & & & & & \\
\hline Number of obs. & 5,489 & & 5,489 & & 5,489 & & 7,315 & & 7,315 & & 7,315 & \\
\hline Number of groups & & & 1,865 & & 1,865 & & & & 2,119 & & 2,119 & \\
\hline \multicolumn{13}{|l|}{$\mathrm{H}_{0}:$ Pooled=Random } \\
\hline Prob $>\chi^{2}$ & & & 0.0000 & & & & & & 0.0000 & & & \\
\hline \multicolumn{13}{|l|}{$\mathrm{H}_{0}$ : Random=Fixed } \\
\hline Prob $>\chi^{2}$ & & & & & 0.0015 & & & & & & 0.0000 & \\
\hline \multicolumn{13}{|l|}{$\mathrm{H}_{0}$ : Pooled=Fixed effect } \\
\hline Prob $>F$ & & & & & 0.0000 & & & & & & 0.0000 & \\
\hline
\end{tabular}

Standard errors in parentheses. ${ }^{* * *} p<0.01,{ }^{* *} p<0.05,{ }^{*} p<0.1$.

2007 Employment Status Survey (ESS), which is a designated statistics survey under the Statistical Law conducted by the Ministry of Internal Affairs and Communications since the distribution of educational attainment of the Population Census in the correspondent year is not publically available. The "unemployment rate" is $5.2 \%$, the percentage of being out of work is $7.3 \%$ among men aged 20 to 39 , and $34.8 \%$ of them are college educated in the $\mathrm{ESS}^{28)}$. This implies that the sample of JLPS is relatively more educated. Because many cases lack information on household income, the final sample size of people with household information is 5,489; if those who had not pro- 
Table 3. Being out of work and mental health measured by MHI-5

\begin{tabular}{|c|c|c|c|c|c|c|c|c|c|c|c|c|}
\hline & \multicolumn{6}{|c|}{ Model 1} & \multicolumn{6}{|c|}{ Model 2} \\
\hline & \multicolumn{2}{|c|}{ Pooled OLS } & \multicolumn{2}{|c|}{ Random effects model } & \multicolumn{2}{|c|}{ Fixed effects model } & \multicolumn{2}{|c|}{ Pooled OLS } & \multicolumn{2}{|c|}{ Random effects model } & \multicolumn{2}{|c|}{ Fixed effects model } \\
\hline & Coef. & Std. Err. & Coef. & Std. Err. & Coef. & Std. Err. & Coef. & Std. Err. & Coef. & Std. Err. & Coef. & Std. Err. \\
\hline Being out of work & $-12.021 * * *$ & 1.348 & $-8.594 * * *$ & 1.288 & $-4.734 * * *$ & 1.632 & $-11.578 * * *$ & 0.982 & $-6.831 * * *$ & 0.975 & $-3.925^{* * *}$ & 1.168 \\
\hline Age & -0.283 & 0.494 & $0.999 *$ & 0.575 & & & -0.616 & 0.422 & 0.645 & 0.496 & & \\
\hline Age squared & 0.007 & 0.008 & -0.013 & 0.009 & $-0.052 * * *$ & 0.013 & $0.012 *$ & 0.006 & -0.008 & 0.008 & $-0.037 * * *$ & 0.011 \\
\hline Junior high school & $-1.659 * *$ & 0.679 & -1.256 & 1.014 & & & -0.723 & 0.580 & -0.711 & 0.910 & & \\
\hline College or more & 0.803 & 0.569 & 0.988 & 0.836 & & & $1.548 * * *$ & 0.477 & $1.779 * *$ & 0.742 & & \\
\hline Married & $-1.265^{* *}$ & 0.512 & -0.224 & 0.430 & -0.243 & 0.481 & $-0.911 * *$ & 0.431 & 0.084 & 0.352 & 0.105 & 0.380 \\
\hline Year 2008 & $-1.478 * *$ & 0.721 & $-1.360 * *$ & 0.533 & $2.152 * *$ & 1.013 & -0.881 & 0.608 & $-0.866 * *$ & 0.436 & $1.623 *$ & 0.831 \\
\hline Year 2009 & $-2.157^{* * *}$ & 0.739 & $-1.678 * * *$ & 0.559 & $5.669 * * *$ & 1.841 & $-1.286^{* *}$ & 0.635 & $-1.193 * *$ & 0.471 & $3.910 * * *$ & 1.503 \\
\hline Year 2010 & $-2.737 * * *$ & 0.766 & $-3.183 * * *$ & 0.598 & $7.421 * * *$ & 2.744 & $-2.584 * * *$ & 0.663 & $-2.987 * * *$ & 0.509 & $4.554 * *$ & 2.228 \\
\hline Year 2011 & $-2.042 * * *$ & 0.755 & $-2.018 * * *$ & 0.612 & $12.526^{* * *}$ & 3.667 & $-1.601 * *$ & 0.658 & $-1.703 * * *$ & 0.526 & $8.541 * * *$ & 2.971 \\
\hline Household income/Person & $0.000^{* * *}$ & 0.000 & $0.000^{* * *}$ & 0.000 & 0.000 & 0.000 & & & & & & \\
\hline Constant & $64.391 * * *$ & 7.994 & $44.279 * * *$ & 9.207 & $117.845^{* * *}$ & 13.825 & $71.267 * * *$ & 6.736 & $50.451 * * *$ & 7.881 & $100.625 * * *$ & 11.073 \\
\hline sigma_u & & & 13.157 & & 25.193 & & & & 12.910 & & 20.669 & \\
\hline sigma_e & & & 12.069 & & 12.069 & & & & 12.186 & & 12.186 & \\
\hline rho & & & 0.543 & & 0.813 & & & & 0.529 & & 0.742 & \\
\hline Prob $>\chi^{2}$ & & & 0.000 & & & & & & 0.000 & & & \\
\hline Prob $>F$ & & & & & 0.0000 & & & & & & 0.000 & \\
\hline R-squared & 0.033 & & & & 0.0025 & & 0.0259 & & 0.023 & & 0.001 & \\
\hline Number of obs. & 5,489 & & 5,489 & & 5,489 & & 7,315 & & 7,315 & & 7,315 & \\
\hline Number of groups & & & 1,865 & & 1,865 & & & & 2,119 & & 2,119 & \\
\hline \multicolumn{13}{|l|}{$\mathrm{H}_{0}$ : Pooled=Random } \\
\hline Prob $>\chi^{2}$ & & & 0.0000 & & & & & & 0.0000 & & & \\
\hline $\mathrm{H}_{0}:$ Random=Fixed & & & & & 0.0000 & & & & & & 0.0000 & \\
\hline \multicolumn{13}{|l|}{ Prob $>\chi^{2}$} \\
\hline $\mathrm{H}_{0}$ : Pooled=Fixed effect & & & & & 0.0000 & & & & & & 0.0000 & \\
\hline Prob $>F$ & & & & & & & & & & & & \\
\hline
\end{tabular}

Standard errors in parentheses. $* * * p<0.01, * * p<0.05, * p<0.1$.

vided income information are included, the sample size is 7,315

There is a clear difference in health between the employed and the being out of work. The average self-assessed health is 2.8 and 3.4 among the being out of work and the employed, respectively. A prominent difference in mental health scores is also observed. The average MHI- 5 scores are 62.9 and 50.8 among the employed and the being out of work, respectively. Because the cut-off point of the MHI5 for depression is generally placed at about $50^{19}$ ), people who are out of work are clearly more likely to be depressed.

Table 2 shows the association between employment status and self-assessed health. The first three columns show the estimated results of Model 1, which includes household income as an explanatory variable. The crosssectional analysis shows a strong negative correlation between being out of work and self-assessed health. The random effects model, which assumes that unobserved individual effects are random, shows that being out of work has a negative effect on health. However, the fixed effects model shows that being out of work has no effect on self- assessed health. According to the statistical tests that the author conducted (Houseman, Breusch, and Pagan tests, and the F-test), the random effects model is more suitable than the cross-sectional model, while the fixed effects model is the most suitable of all. Therefore, the results of the fixed effects model are accepted. In every set of results, the effect of household income per capita on health is statistically significant and positive. This is consistent with previous research ${ }^{26,27)}$. In Model 2, which excludes household income, it is found that the effect of being out of work on health in the fixed effects model is significant and negative, likely because, in this model, being out of work includes the effect of income loss.

Table 3 shows the relationship between employment status and mental health. The first column shows a strong correlation between being out of work and mental health. If an individual is not working, his MHI-5 score decreases by 12.0 points. The coefficients of being out of work are -8.6 and -4.7 in the random effects and the fixed effects models, respectively, and they are statistically significant. The last three columns present the results of Model 2, 
Table 4. Summary statistics of sab-samples

\begin{tabular}{|c|c|c|c|c|c|c|}
\hline \multirow{2}{*}{ Variable } & \multicolumn{2}{|c|}{ All } & \multicolumn{2}{|c|}{ Employed } & \multicolumn{2}{|c|}{ Out of work } \\
\hline & Mean & Std. Dev. & Mean & Std. Dev. & Mean & Std. Dev. \\
\hline Self-rated health $(1-5)$ & 3.413 & 0.881 & 3.425 & 0.877 & 3.102 & 0.919 \\
\hline MHI-5 score $(0-100)$ & 63.037 & 17.378 & 63.334 & 17.270 & 55.398 & 18.430 \\
\hline Being out of work & 0.037 & 0.190 & & & & \\
\hline Age & 33.103 & 5.555 & 33.145 & 5.550 & 32.023 & 5.597 \\
\hline Age squared & $1,126.657$ & 362.352 & $1,129.377$ & 362.220 & $1,056.667$ & 359.401 \\
\hline Education: High school or less & 0.321 & 0.467 & 0.317 & 0.465 & 0.409 & 0.493 \\
\hline Education: Junior high school & 0.208 & 0.406 & 0.206 & 0.404 & 0.258 & 0.438 \\
\hline Education: College or more & 0.472 & 0.499 & 0.477 & 0.500 & 0.333 & 0.472 \\
\hline Married & 0.442 & 0.497 & 0.437 & 0.496 & 0.580 & 0.495 \\
\hline Household income per person (yen) & $3,803,454$ & $2,258,667$ & $3,839,570$ & $2,255,038$ & $2,408,407$ & $1,940,520$ \\
\hline Number of observations & 7,057 & & 6,793 & & 264 & \\
\hline $\begin{array}{l}\text { Number of observations (with information } \\
\text { about household income) }\end{array}$ & 5,310 & & 5,176 & & 134 & \\
\hline
\end{tabular}

Table 5. Being out of work and self-assessed health (with Sub-sample)

\begin{tabular}{|c|c|c|c|c|c|c|c|c|c|c|c|c|}
\hline & \multicolumn{6}{|c|}{ Model 1} & \multicolumn{6}{|c|}{ Model 2} \\
\hline & \multicolumn{2}{|c|}{ Pooled OLS } & \multicolumn{2}{|c|}{ Random effects model } & \multicolumn{2}{|c|}{ Fixed effects model } & \multicolumn{2}{|c|}{ Pooled OLS } & \multicolumn{2}{|c|}{ Random effects model } & \multicolumn{2}{|c|}{ Fixed effects model } \\
\hline & Coef. & Std. Err. & Coef. & Std. Err. & Coef. & Std. Err. & Coef. & Std. Err. & Coef. & Std. Err. & Coef. & Std. Err. \\
\hline Being out of work & $-0.214^{* * *}$ & 0.077 & -0.101 & 0.072 & 0.025 & 0.093 & $-0.301 * * *$ & 0.055 & $-0.147 * * *$ & 0.053 & 0.003 & 0.065 \\
\hline Age & -0.025 & 0.025 & -0.031 & 0.029 & & & -0.020 & 0.021 & -0.015 & 0.025 & & \\
\hline Age squared & 0.000 & 0.000 & 0.000 & 0.000 & 0.000 & 0.001 & 0.000 & 0.000 & 0.000 & 0.000 & 0.000 & 0.001 \\
\hline Junior high school & 0.049 & 0.034 & 0.051 & 0.049 & & & $0.074 * *$ & 0.029 & 0.070 & 0.045 & & \\
\hline College or more & $0.155^{* * *}$ & 0.028 & $0.166^{* * *}$ & 0.040 & & & $0.207^{* * *}$ & 0.024 & $0.221^{* * *}$ & 0.036 & & \\
\hline Married & $-0.064^{* *}$ & 0.026 & -0.028 & 0.022 & -0.020 & 0.025 & $-0.053 * *$ & 0.022 & -0.017 & 0.018 & -0.005 & 0.020 \\
\hline Year 2008 & -0.020 & 0.036 & -0.031 & 0.028 & -0.075 & 0.053 & 0.008 & 0.030 & 0.004 & 0.023 & -0.017 & 0.043 \\
\hline Year 2009 & $-0.191 * * *$ & 0.037 & $-0.192 * * *$ & 0.029 & $-0.260 * * *$ & 0.097 & $-0.163 * * *$ & 0.032 & $-0.163 * * *$ & 0.024 & $-0.197 * *$ & 0.078 \\
\hline Year 2010 & -0.055 & 0.038 & $-0.094 * * *$ & 0.031 & -0.211 & 0.145 & -0.051 & 0.033 & $-0.087^{* * *}$ & 0.026 & -0.152 & 0.116 \\
\hline Year 2011 & $-0.141 * * *$ & 0.038 & $-0.161 * * *$ & 0.031 & -0.294 & 0.193 & $-0.144 * * *$ & 0.033 & $-0.166^{* * *}$ & 0.027 & -0.245 & 0.155 \\
\hline Household income/Person & $0.000^{* * *}$ & 0.000 & $0.000^{* * *}$ & 0.000 & $0.000^{* * *}$ & 0.000 & & & & & & \\
\hline Constant & $3.954 * * *$ & 0.399 & $4.008^{* * *}$ & 0.456 & $3.194 * * *$ & 0.729 & $3.881^{* * *}$ & 0.336 & $3.741^{* * *}$ & 0.395 & $3.371 * * *$ & 0.577 \\
\hline sigma_u & & & 0.602 & & 0.768 & & & & 0.618 & & 0.755 & \\
\hline sigma_e & & & 0.621 & & 0.621 & & & & 0.619 & & 0.619 & \\
\hline rho & & & 0.484 & & 0.604 & & & & 0.499 & & 0.598 & \\
\hline Prob $>\chi^{2}$ & & & 0.000 & & & & & & & & & \\
\hline Prob $>F$ & & & & & 0.0000 & & & & & & 0.000 & \\
\hline R-squared & 0.030 & & 0.0305 & & 0.0028 & & 0.0265 & & 0.026 & & 0.002 & \\
\hline Number of obs. & 5,310 & & 5,310 & & 5,310 & & 7,057 & & 7,057 & & 7,057 & \\
\hline Number of groups & & & 1,843 & & 1,843 & & & & 2,106 & & 2,106 & \\
\hline \multicolumn{13}{|l|}{$\mathrm{H}_{0}$ : Pooled=Random } \\
\hline Prob $>\chi^{2}$ & & & 0.0000 & & & & & & 0.0000 & & & \\
\hline \multicolumn{13}{|l|}{$\mathrm{H}_{0}$ : Random=Fixed } \\
\hline Prob $>\chi^{2}$ & & & & & 0.0302 & & & & & & 0.0009 & \\
\hline \multicolumn{13}{|l|}{$\mathrm{H}_{0}$ : Pooled=Fixed effect } \\
\hline Prob $>F$ & & & & & 0.0000 & & & & & & 0.0000 & \\
\hline
\end{tabular}

Standard errors in parentheses. $* * * p<0.01, * * p<0.05, * p<0.1$.

which do not control for household income. Surprisingly, the effect of being out of work on mental health is smaller in each equation, unlike the results for self-assessed health. A possible explanation for this is that the estimations for samples with and without household income differed. Furthermore, the sample containing only those with household income information is smaller than the sample containing all the respondents. Therefore, the effect of being out of work on mental health might be stronger in people suffering from serious psychological distress. Regardless of the estimation methods, it is found that being out of work has a negative effect on mental health, even when controlling 
Table 6. Being out of work and mental health measured by MHI-5 (with Sub-sample)

\begin{tabular}{|c|c|c|c|c|c|c|c|c|c|c|c|c|}
\hline & \multicolumn{6}{|c|}{ Model 1} & \multicolumn{6}{|c|}{ Model 2} \\
\hline & \multicolumn{2}{|c|}{ Pooled OLS } & \multicolumn{2}{|c|}{ Random effects model } & \multicolumn{2}{|c|}{ Fixed effects model } & \multicolumn{2}{|c|}{ Pooled OLS } & \multicolumn{2}{|c|}{ Random effects model } & \multicolumn{2}{|c|}{ Fixed effects model } \\
\hline & Coef. & Std. Err. & Coef. & Std. Err. & Coef. & Std. Err. & Coef. & Std. Err. & Coef. & Std. Err. & Coef. & Std. Err. \\
\hline Being out of work & $-6.970 * * *$ & 1.524 & $-5.851 * * *$ & 1.402 & $-3.582 * *$ & 1.760 & $-7.433 * * *$ & 1.088 & $-5.349 * * *$ & 1.037 & $-3.940 * * *$ & 1.250 \\
\hline Age & -0.269 & 0.491 & 0.876 & 0.571 & & & $-0.697^{*}$ & 0.418 & 0.529 & 0.492 & & \\
\hline Age squared & 0.007 & 0.007 & -0.011 & 0.009 & $-0.048 * * *$ & 0.013 & $0.014 * *$ & 0.006 & -0.005 & 0.008 & $-0.035^{* * *}$ & 0.011 \\
\hline Junior high school & $-1.324 *$ & 0.680 & -1.050 & 1.009 & & & -0.469 & 0.579 & -0.678 & 0.899 & & \\
\hline College or more & 0.630 & 0.566 & 0.790 & 0.828 & & & $1.420 * * *$ & 0.473 & $1.505 * *$ & 0.732 & & \\
\hline Married & $-1.074 * *$ & 0.510 & -0.016 & 0.430 & -0.119 & 0.483 & -0.694 & 0.429 & 0.263 & 0.352 & 0.182 & 0.381 \\
\hline Year 2008 & -1.151 & 0.717 & $-1.176^{* *}$ & 0.532 & $1.952 *$ & 1.016 & -0.596 & 0.603 & $-0.741 *$ & 0.435 & $1.594 *$ & 0.833 \\
\hline Year 2009 & $-2.300 * * *$ & 0.734 & $-1.837 * * *$ & 0.558 & $4.942 * * *$ & 1.846 & $-1.387 * *$ & 0.631 & $-1.230 * * *$ & 0.470 & $3.728 * *$ & 1.507 \\
\hline Year 2010 & $-2.521 * * *$ & 0.763 & $-3.043^{* * *}$ & 0.597 & $6.675^{* *}$ & 2.753 & $-2.523 * * *$ & 0.660 & $-2.946 * * *$ & 0.508 & $4.344 *$ & 2.235 \\
\hline Year 2011 & $-2.041 * * *$ & 0.748 & $-1.956^{* * *}$ & 0.609 & $11.498 * * *$ & 3.677 & $-1.536^{* *}$ & 0.652 & $-1.580 * * *$ & 0.523 & $8.383 * * *$ & 2.981 \\
\hline Household income/Person & $0.000 * * *$ & 0.000 & $0.000 * * *$ & 0.000 & 0.000 & 0.000 & & & & & & \\
\hline Constant & $64.022 * * *$ & 7.936 & $46.055^{* * *}$ & 9.139 & $113.575^{* * *}$ & 13.862 & $71.975 * * *$ & 6.678 & $52.140 * * *$ & 7.812 & $99.619 * * *$ & 11.109 \\
\hline sigma_u & & & 12.970 & & 23.884 & & & & 12.677 & & 20.188 & \\
\hline sigma_e & & & 11.823 & & 11.823 & & & & 11.926 & & 11.926 & \\
\hline rho & & & 0.546 & & 0.803 & & & & 0.530 & & 0.741 & \\
\hline Prob $>\chi^{2}$ & & & 0.0000 & & & & & & 0.000 & & & \\
\hline Prob $>F$ & & & & & 0.0000 & & & & & & 0.000 & \\
\hline R-squared & 0.0187 & & 0.0174 & & 0.0044 & & 0.0138 & & 0.012 & & 0.003 & \\
\hline Number of obs. & 5,310 & & 5,310 & & 5,310 & & 7,057 & & 7,057 & & 7,057 & \\
\hline Number of groups & & & 1,843 & & 1,843 & & & & 2,106 & & 2,106 & \\
\hline \multicolumn{13}{|l|}{$\mathrm{H}_{0}$ : Pooled=Random } \\
\hline Prob $>\chi^{2}$ & & & 0.0000 & & & & & & 0.0000 & & & \\
\hline \multicolumn{13}{|l|}{$\mathrm{H}_{0}$ : Random=Fixed } \\
\hline Prob $>\chi^{2}$ & & & & & 0.0000 & & & & & & 0.0008 & \\
\hline \multicolumn{13}{|l|}{$\mathrm{H}_{0}$ : Pooled=Fixed effect } \\
\hline Prob $>F$ & & & & & 0.0000 & & & & & & 0.0000 & \\
\hline
\end{tabular}

Standard errors in parentheses. $* * * p<0.01, * * p<0.05, * p<0.1$.

for household income.

Finally, Table 4 depicts the descriptive statistics for the sub-sample, and Tables 5 and 6 summarize the regression results for this sub-sample. Because the sub-sample does not contain people who had always or often been restricted in their housework or job because of health problems, the average self-assessed health and MHI-5 scores are higher than that of the whole sample.

Comparing Tables 2 and 5, the coefficient for being out of work is much smaller in the sub-sample. In Model 1, only the results from the cross-sectional analysis show a statistically significant negative effect: after excluding people who had always or often been restricted in their housework or job due to health problems, a negative correlation between being out of work and self-assessed health is still observed. However, this effect disappears when the panel analysis is conducted.

In Table 6, the coefficients of being out of work are all significant and negative. This implies that being out of work affects mental health even after excluding people who have had health problems that disturb their work and daily life, and even after controlling for individual heterogeneity and household income. In comparing the coefficients of being out of work in Tables 3 and 6, it is noted that they are smaller in Table 6 in each model.

\section{Discussion}

Using the first through the fifth waves of the JLPS (whose first wave was conducted in 2007), a fixed effects model analyses found no effect of being out of work on selfassessed physical health. The reason for this finding could be that a stronger correlation arises from self-selectivity. That is, people who have poor health tend to be out of work. This is likely why negative associations between unemployment and self-assessed health have been extensively observed in cross-sectional research. Therefore, when individual heterogeneity is controlled for, the effect disappears.

However, the results from the model that excludes household income from the explanatory variables show a negative effect of being out of work on self-assessed 
physical health, even after controlling for individual heterogeneity. The different results between Models 1 and 2 pertain to the effects of income on self-assessed health, which are substantial according to the health inequality literature. In addition, employment status and household income are intrinsically linked. Therefore, if being out of work includes loss of income, the effect of being out of work on health should be statistically significant. Because Model 1 separates the effect of being out of work from the effect of income, it indicates that being out of work itself does not affect self-assessed physical health.

Regarding the effect of being out of work on mental health as measured by the MHI-5, the fixed effects model analysis shows that being out of work has a negative effect on mental health. In addition, the effect of employment status is statistically significant even after controlling for income, which is not observed for self-assessed physical health. Thus, being out of work itself likely has a negative impact on mental health.

Comparing the descriptive statistics between the whole sample and the sub-sample, the MHI-5 scores among the being out of work significantly differ between these two groups. This implies that people who have limitations in their daily life due to health suffer more psychological distress from being out of work. The relationship between work limitations and mental health would be an important topic in future research.

\section{Limitations}

Although a fixed effects model analysis can eliminate the problem of self-selection bias, possible simultaneity problems remain - that is, in addition to the impact of being out of work on health, employment status often changes when health conditions change. An analysis using a sub-sample of people who had not been limited in their daily activities due to health reasons in the past month was conducted to mitigate the problem related to reverse causality. The results from the whole sample and from the sub-sample are consistent, but there is a clear difference in the magnitude of the coefficients of being out of work. This implies that health condition affects employment status and it is difficult to clearly distinguish the direction of causality even after controlling for individual heterogeneity that is constant over time. Thus, a more ecologically valid experiment, such as using data from plant closures, would be a more effective strategy for distinguishing the effect of being out of work or "unemployment" on health from the effect of health on employment status.

\section{References}

1) Japan Ministry of Internal Affairs and Communications Labour Force Survey, Historical Data. http://www.stat. go.jp/english/data/roudou/lngindex.htm. Accessed July 28, 2013.

2) OECD (2010) Employment Outlook 2010: Moving beyond the Jobs Crisis, OECD, Paris.

3) Ono H (2010) Lifetime employment in Japan: concepts and measurements. J Jpn Int Econ 24, 1-27. [CrossRef]

4) Jin RL, Shah C P, Svobada TJ (1995) The impact of unemployment on health: a review of the evidence. CMAJ 153, 529-40. [Medline]

5) Togari Y (2008) The examination of relationship between "marriage and employment formats" and "health and healthy life styles". Japanese Life Course Panel Survey Discussion Paper No. 9, 1-31 (in Japanese).

6) Nakazawa W (2010) Panel data analysis of mental health. Ann Toyo Univ Sch Sociol 47, 83-96.

7) Böckerman P, Ilmakunnas P (2009) Unemployment and self-assessed health: evidence from panel data. Health Econ 18, 161-79. [Medline] [CrossRef]

8) Morris JK, Cook DG (1991) A critical review of the effect of factory closures on health. Br J Ind Med 48, 1-8. [Medline]

9) Browning M, Dano AM, Heinesen E (2006) Job displacement and stress-related health outcomes. Health Econ 15, 1061-75. [Medline] [CrossRef]

10) Salm M (2009) Does job loss cause ill health? Health Econ 18, 1075-89. [Medline] [CrossRef]

11) Cai L (2010) The relationship between health and labour force participation: evidence from a panel data simultaneous equation model. Labour Econ 17, 77-90. [CrossRef]

12) Goldman-Mellor SJ, Saxton KB, Catalano RC (2010) Economics contraction and mental health. Int $\mathrm{J}$ Ment Health 39, 6-31. [CrossRef]

13) Schmitz H (2011) Why are the unemployed in worse health? The causal effect of unemployment on health. Labour Econ 18, 71-8. [CrossRef]

14) Green F (2011) Unpacking the misery multiplier: how employability modifies the impacts of unemployment and job insecurity on life satisfaction and mental health. $\mathrm{J}$ Health Econ 30, 265-76. [Medline] [CrossRef]

15) Akabayashi H (2006) The labor supply of married women and spousal tax deductions in Japan - a structural estimation. Rev Econ Househ 4, 349-78. [CrossRef]

16) Cheng BS, Hsu RC, Chu Q (1997) The causality between fertility and female labour force participation in Japan. Appl Econ Lett 4, 113-5. [Medline] [CrossRef]

17) Shimizutani S, Suzuki W, Noguchi H (2008) The socialization of at-home elderly care and female labor market participation: micro-level evidence from Japan. Japan World Econ 20, 82-96. [CrossRef]

18) Veit CT, Ware JE (1983) The structure of psychological 
distress and well-being in general populations. J Consult Clin Psychol 51, 730-42. [Medline] [CrossRef]

19) Berwick DM, Murphy JM, Goldman PA, Ware JE Jr, Barsky AJ, Weinstein MC (1991) Performance of a fiveitem mental health screening test. Med Care 29, 169-76. [Medline] [CrossRef]

20) Yamazaki S, Fukuhara S, Green J (2005) Usefulness of five-item and three-item mental health inventories to screen for depressive symptoms in the general population of Japan. Health Qual Life Outcomes 3, 48. [Medline] [CrossRef]

21) Ware JE, Snow KK, Kosinski M, Gadek B (1993) SF36 Health survey manual and interpretation guide, New England Medical Center, Boston.

22) Hsiao C (2003) Analysis of panel data, 2nd Ed., Cambridge University, Cambridge.
23) Klevmarken NA (1989) Panel studies: what can we learn from them? Introduction. Eur Econ Rev 33, 523-9. [CrossRef]

24) Baltagi BH (2008) Economic analysis of panel data, 4th Ed., John Wiley and Sons, Chichester.

25) Mundlak Y (1978) On the pooling of time series and cross section data. Econometrica 46, 69-85. [CrossRef]

26) Hausman JA (1978) Specification test in econometrics. Econometrica 46, 1251-71. [CrossRef]

27) Wooldridge JM (2002) Economic analysis of cross section and panel data, The MIT Press, Cambridge.

28) Ministry of Internal Affairs and Communications (2007) Employment Status Survey, National Data. http://www. e-stat.go.jp/SG1/estat/NewList.do?tid=000001017285 (in Japanese). Accessed July 28, 2013. 